\title{
Extratropical sources of Equatorial Pacific upwelling in an OGCM
}

\author{
Keith B. Rodgers' \\ IPSL/LSCE, Gif sur Yvette, France \\ Bruno Blanke \\ Laboratoire de Physique des Océans, (CNRS/IFREMER/UBO), Brest, France \\ Gurvan Madec and Olivier Aumont \\ LODYC (CNRS/IRD/UPMC), Paris, France
}

Philippe Ciais and Jean-Claude Dutay

IPSL/LSCE, Gif sur Yvette, France

Received 30 July 2002; accepted 11 December 2002; published 29 January 2003.

[1] The extratropical sources of equatorial undercurrent (EUC) water have been identified for an ocean circulation model using Lagrangian trajectory analysis. It has been found that the EUC waters emenate from a wide range of latitudes in the Pacific basin, with its densest constituent watermass being Subantarctic Mode Water (SAMW) from $50^{\circ} \mathrm{S}$. Further analysis of the basin-scale circulation fields has revealed significant advective diapycnal mass fluxes associated with intergyre exchange. As a result of these diapycnal mass fluxes, the EUC transport as a function of density at $151^{\circ} \mathrm{W}$ (an Eulerian diagnostic) looks quite different from the original subduction rate as a function of density for the same collection of water particles. This implicates diapycnal vertical mixing as an important player in determining the preferred density horizon of maximum EUC transport along the equator. In summary, these results illustrate an important interdependence between advective and diapycnal mixing processes associated with basin-scale inter-gyre and inter-basin exchange in determining the mean equatorial stratification and EUC structure. INDEX TERMS: 4231 Oceanography: General: Equatorial oceanography; 4279 Oceanography: General: Upwelling and convergences; 4283 Oceanography: General: Water masses; 4255 Oceanography: General: Numerical modeling. Citation: Rodgers, K. B., B. Blanke, G. Madec, O. Aumont, P. Ciais, and J.-C. Dutay, Extratropical sources of Equatorial Pacific upwelling in an OGCM, Geophys. Res. Lett., 30(2), 1084, doi:10.1029/ 2002GL016003, 2003.

\section{Introduction}

[2] In this paper we seek to identify the dynamical processes responsible for maintaining the mean stratification of the equatorial Pacific thermocline. A variety of processes, ranging from local to global-scale, contribute to this. An example of a local process is the strong vertical mixing and entrainment that occurs in high-shear regions

\footnotetext{
'Now at LODYC, Paris, France.
}

Copyright 2003 by the American Geophysical Union. $0094-8276 / 03 / 2002$ GL016003\$05.00 such as the EUC [Johnson and McPhaden, 1999]. On the other hand, the equatorial Pacific thermocline is known to be connected to the global ocean circulation via advective exchanges with the extratropical gyres of the Pacific, as well as with the Southern and Indian Occans [Gordon, 1986]. It has previously been shown in forced ocean model experiments [Hirst and Godfrey, 1993; Murtugudde et al., 1998; Rodgers et al., 1999] that the stratification of the equatorial Pacific thermocline is sensitive to inter-basin exchanges with the Indian Ocean via the Indonesian Throughflow.

[3] Tsuchiya [1981, 1989] used salinity measurements to address the extratropical sources of the $13^{\circ} \mathrm{C}$ mode water which is found in the lower reaches of the EUC for the eastern equatorial Pacific. He proposed source regions which lie to the northeast of New Zealand and in the Tasman Sea. Toggweiler et al. [1991] used $\triangle^{14} \mathrm{C}$ to argue for the presence of Sub-Antarctic Mode Water (SAMW) in the untritiated (i.e. free of bomb- ${ }^{14} \mathrm{C}$ ) EUC, which is further to the south than the principal source region proposed by Tsuchiya.

[4] Our primary objectives are threefold. First, we wish to identify the extratropical source regions for the EUC water. Our second objective is to use the Lagrangian trajectory analysis tool to identify whether the watermass transformation processes associated with intergyre exchange are significant or negligible. The Lagrangian trajectories are calculated using the model advective fields (mixing information is only implicitly contained in these fields), and thus the magnitude of the diapycnal mass flux is integrated over the inter-gyre exchange process. Third, we wish to use the Lagrangian trajectories to estimate both the flux and modelderived intergyre exchange timescale for SAMW, as SAMW may be an important oceanic sink of anthropogenic $\mathrm{CO}_{2}$.

\section{Model Description}

[5] The ocean circulation model used for this study is the version 8.1 release of OPA, Ocean Parallelisé [Madec et al, 19981. The global domain extends from $78^{\circ} \mathrm{S}$ to $90^{\circ} \mathrm{N}$. The bottom topography and coastlines are derived from the study of Smith and Sandwell [1997], complemented by the ETOPO5 data set. Lateral mixing is oriented isopycnally, and the eddy parameterization scheme of Gent and 
McWilliams [1990] is applied poleward of $10^{\circ}$. Vertical mixing is achieved using the TKE scheme of Blanke and Delectuse [1993].

[i] The particular model configuration used is ORCA2, for which the zonal resolution is $2^{\circ}$, and meridional resolution ranges from $0.5^{\circ}$ at the equator to $2^{\circ} \times \cos ($ latitude) poleward of $20^{\circ}$. The model grid is tripolar, with two poles in the Northern Hemisphere (over North America and Siberia) and one centered over Antarctica. The model uses 30 layers in the vertical, with 20 of these layers lying in the upper 500 meters. Thus, the model resolves the critical scales of the equatorial circulation and upwelling, and also includes sufficient vertical resolution to address the intergyre exchange of thermocline and mode waters for the Pacific basin. The ocean model is coupled to a sea ice model [Fichefet and Morales Maqueda, 1997; Goosse and Fichefet, 1999].

[7] The model was initialized with Boyer et al. [1998] and Antonov et al. [1998] salinity and temperature climatologies, and then spun up for 100 years with climatological fluxes taken from the NCEP reanalysis [Kalnay et al., 1996]. Sea surface salinity was restored to climatological values with a time constant of two months, and surface heat fluxes were calculated using bulk formulas. A circulation climatology was constructed from the last five years of the model spinup, and it is this climatology that was analyzed with the Lagrangian trajectory analysis.

[8] The Lagrangian trajectory analysis presented here builds on the previous studies for the Pacific of Blanke and Raynaud [1997] and for the Atlantic of Hazeleger et al. [2003]. The former included a detailed analysis of the zonal structure of the EUC, although they did not explicitly consider its extratropical source regions. As in their study, the EUC is here defined at $151^{\circ} \mathrm{W}$ as all water moving eastward between $3^{\circ} \mathrm{N}$ and $3^{\circ} \mathrm{S}$, and between the base of the surface mixed layer and $612 \mathrm{~m}$ depth. The particles were released then into the reverse model circulation fields within the EUC at $151^{\circ} \mathrm{W}$, and advected until they intercepted the base of the mixed layer (defined using a $0.01 \mathrm{~kg} / \mathrm{m}^{3}$ threshold). A sum total of 13,000 particles were released.

[0] The Lagrangian trajectories are not intended to simulate the motions of individual water parcels or molecules within the ocean. Rather, they represent streamlines within the large-scale velocity fields calculated by the OGCM. We computed three-dimensional trajectories in this time-varying velocity field. One must keep in mind however that this field includes the mean effect of turbulent mixing (diffusion) on the momentum equations, as calculated by the ocean model with its parameterizations of sub-gridscale turbulence.

\section{Results}

[10] The source regions for the EUC, whose mean transport is $30.8 \mathrm{~Sv}$, are shown for the Pacific basin in Figure 1. This indicates the points at which the parcels intercept the base of the mixed layer, with individual parcels indicated by colored circles. The colors (scale shown in lower left corner) represent the respective densities for these same particles when they cross $151^{\circ} \mathrm{W}$ within the EUC.

[11] For both the Northern and Southern Hemispheres, the source regions encompass a wide range of latitudes. In the Southern Hemisphere, which is the origin of $2 / 3$ of the

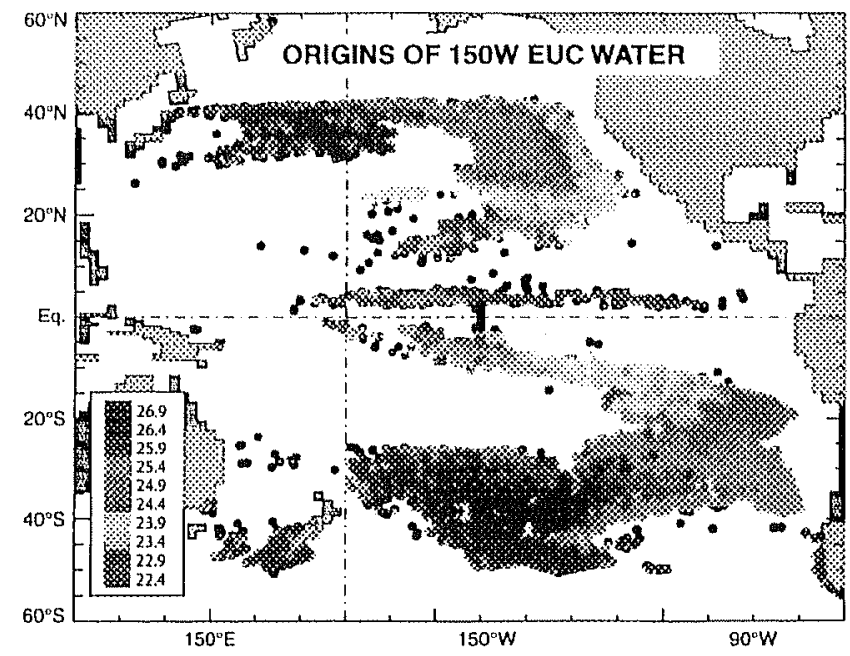

Figure 1. Source regions of the EUC identified with Lagrangian trajectories. The particles were released within the EUC at $151^{\circ} \mathrm{W}$ (see text for EUC definition; the section at $151^{\circ} \mathrm{W}$ is marked with a solid black line), and advected with the reverse model circulation fields until they intersected the base of the mixed layer (defined using a 0.01 difference in density in $\sigma_{0}$ units). The densities of the particles within the EUC at $151^{\circ} \mathrm{W}$ are shown in color.

water in the EUC, the particles originate from latitudes as far away as $50^{\circ} \mathrm{S}$. This area corresponds to the SAMW (Sub Antarctic Mode Water) production region.

[12] Over the South Pacific, the source regions form a broad arc, which ranges from the central part of the basin at $50^{\circ} \mathrm{S}$ to the eastern regions of the subtropical gyre $\left(15^{\circ} \mathrm{S}\right.$ to $35^{\circ} \mathrm{S}$ ). In the Northern Hemisphere, the particles subduct as far north as $40^{\circ} \mathrm{N}$. Between $15^{\circ} \mathrm{N}$ and $30^{\circ} \mathrm{N}$, the source regions lie in the eastern part of the basin, although between $30^{\circ} \mathrm{N}$ and $42^{\circ} \mathrm{N}\left(42^{\circ} \mathrm{N}\right.$ being the northernmost limit of the source region in the Northern Hemisphere) they extend across the basin. The fact that none of the parcels identified in the figure lie in the subpolar gyre of the North Pacific does not imply that the model is not forming any North Pacific Intermediate Water (NPIW). Rather, the majority of the model NPIW is siphoned into the Indian Ocean via the Indonesian Throughflow before it reaches the equator [Blanke et al., 2001: their Figure 1].

[13] The transports (in units of $\mathrm{m}^{3} / \mathrm{s}$ per $0.1 \sigma_{0}$ unit) are shown for three different stages of the intergyre exchange process in Figure 2. The first of these is subduction (dotted line), i.e. the transports across the base of the mixed layer in the source regions shown in Figure 1 . The second is at the crossing of $10^{\circ} \mathrm{N} / 10^{\circ} \mathrm{S}$ as the particle moves towards the equator (dashed line), and the third is as the particle crosses $151^{\circ} \mathrm{W}$ in the EUC (solid line). Some of the particles released in the EUC and advected with the reverse flowfields are intercepted in the mixed layer before they reach $10^{\circ} \mathrm{N}$ or $10^{\circ} \mathrm{S}$; these particles are included in the dashed line corresponding to the crossing of $10^{\circ} \mathrm{N} / 10^{\circ} \mathrm{S}$.

[14] The subduction rates (dotted line), binned by density and represented as transports, reveal a large peak at $\sigma_{0}=$ 25.2, a minor peak at 26.0 , and a relatively large peak at 26.8 (mode water). The large peak at 25.2 represents the waters which subduct in the eastern subtropics, and the peak 


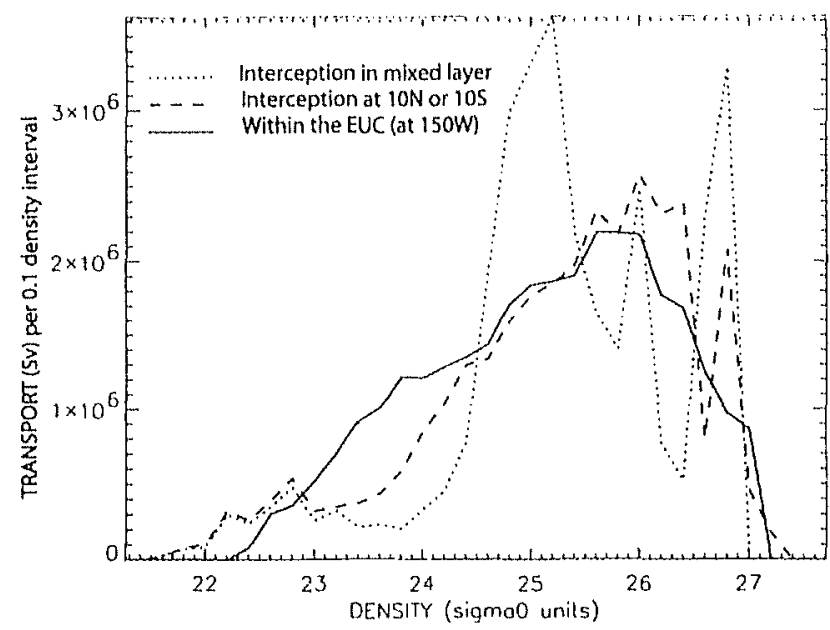

Figure 2. Transport as a function of density (in units of $\mathrm{m}^{3} / \mathrm{s}$ per $0.1 \sigma_{0}$ unit). The dotted line represents the subduction rate, the dashed line represents transports across $10^{\circ} \mathrm{N} / 10^{\circ} \mathrm{S}$, and the solid line represents the particles within the EUC at $151^{\circ} \mathrm{W}$.

at 26.8 corresponds largely to the source region bounded by $150^{\circ} \mathrm{W}$ and $120^{\circ} \mathrm{W}$ in the zonal direction, and $40^{\circ} \mathrm{S}$ and $50^{\circ} \mathrm{S}$ in the meridional direction. For transports within the EUC (solid curve) there is only one peak between $\sigma_{0}=25.6$ and 26.0. The diagnostics at $10^{\circ} \mathrm{N} / 10^{\circ} \mathrm{S}$ (dashed line) reveals a primary peak which is slightly deeper than that within the EUC with a secondary peak near 26.8 .

[15] There are important differences between all three of the curves. First, between subduction and arrival in the EUC the preferred density horizon for subduction $\left(\sigma_{0}=25.2\right)$ disappears, indicating that this watermass has "migrated" to another density horizon via a diapycnal mass flux. Much of this transformation for the mean state occurs between the subduction region and $10^{\circ}$ latitude in the respective hemisphere of subduction. Importantly, the total transport in the density range $\sigma_{0}=26.4$ to 27.0 is much less along the EUC than at the time of subduction. Part of this transformation occurs between the subduction latitude and $10^{\circ} \mathrm{S}\left(10^{\circ} \mathrm{N}\right)$, and part of this occurs within $10^{\circ}$ of the equator.

[16] The advective intergyre exchange timescales for SAMW (here defined as $\sigma_{0}>26.2$ ) were also considered. Figure 3 shows the transit time for the collection of SAMW particles between subduction and arrival at $151^{\circ} \mathrm{W}$ in the EUC. The fastest transit time for SAMW water in the model is 28 years, and only after 92 years have $1 / 2$ of the particles arrived in the EUC. The time required for $3 / 4$ of the particles to reach the EUC is 272 years. The arrival time in the EUC for SAMW is also shown as a spectrum. This has a primary peak between 30 and 50 years, a secondary peak near 80 years, and a third peak near 140 years.

\section{Discussion}

[17] We have seen that the subtropical source regions for the EUC extend quite far south in the Southern Hemisphere. As revealed in Figure 1, the source region at $50^{\circ} \mathrm{S}$ in the west-central South Pacific corresponds to a formation region for SAMW. As such, our results are consistent with the arguments presented by Toggweiler et al. [1991], who used $\triangle^{14} \mathrm{C}$ as a tracer from the Southern Hemisphere to identify SAMW as a source region for EUC waters.

[18] Within the subtropics, the spatial structure found with our model for the sources of EUC water is consistent with previous modeling results obtained for more idealized model geometries [Liu et al, 1994]. For both the North and South Pacific, the source regions tend to be in the eastern part of the basin for the subtropical gyres, as the subduction regions in the central and western parts of the gyres are more likely to be recirculated with the subtropical gyre [Blanke et al., 2002]. At higher latitudes, the source regions are further away from the coast, and this can be understood in terms of the basin-scale structure of the subtropical gyres.

[19] The magnitude of the shift in the density structure of transport associated with intergyre exchange (Figure 2) was an unexpected result. It reveals a large advective diapycnal mass flux during intergyre exchange. In particular, it implies significant exchange of properties across the base of the directly ventilated thermocline at $\sigma_{0}=26.2$ [Johnson and McPhaden, 1999; McPhaden and Zhang, 2002]. For the basin-scale intergyre exchange process, this diapycnal mass flux balances diapycnal mixing processes within the thermocline. Spatially, the diapycnal mass flux occurs in both the extratropics (where the model's diapycnal mixing as calculated by the TKE scheme is small) as well as along the equator (where mixing is relatively large).

[20] The question arises as to whether the diapycnal transformations inferred from Lagrangian trajectory analysis are due to errors in the calculations. We have assumed that the climatology constructed from the output of 24.33(3) day average flowfields (i.e. 15 outputs per year) is able to sample the variability of interest to the seasonal cycle. In light of the model's resolution and surface forcing, this assumption is justified. With the exception of instability waves in the eastem equatorial Pacific, there is little opportunity for the model to develop circulation features with timescales shorter than those of the surface forcing fields.

[21] The analysis presented here has revealed a lack of ventilation in the equatorial region (i.e. between $10^{\circ} \mathrm{N}$ and $10^{\circ} \mathrm{S}$ ). However, this result may be sensitive to the threshold $\left(0.01 \mathrm{~kg} / \mathrm{m}^{3}\right)$ in density units used to characterize the base of the mixed layer. The threshold definition used here may not be well suited for studying the equatorial region, as it is too

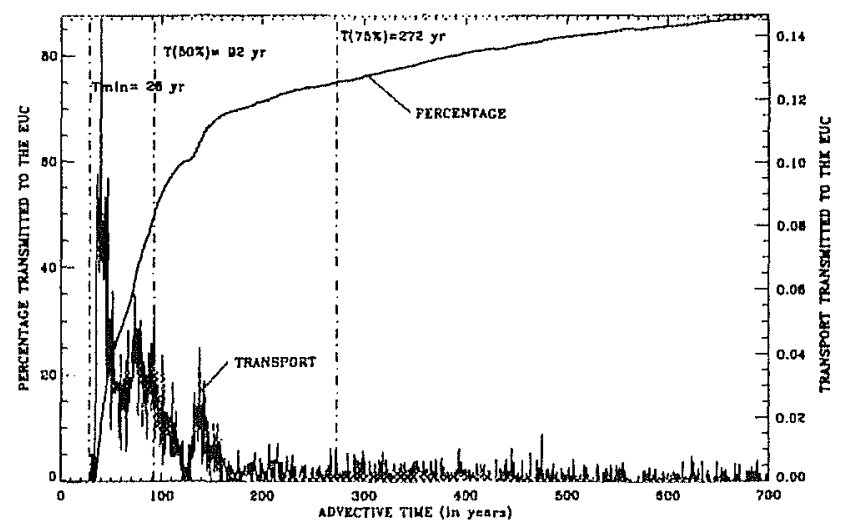

Figure 3. Model derived intergyre exchange timescales for Subantarctic Mode Water (SAMW), defined as water for which $\sigma_{0}>26.2$ at the time of subduction. The exchange timescale is shown cumulatively, and as a spectrum. 
strict, and might lead to a mixed layer depth which is shallower than what one would expect from equatorial dynamics. We leave the sensitivity of these results to this parameterization as a subject for further study.

[22] The advective ages of SAMW calculated by the model are of particular interest to the question of the oceanic uptake of anthropogenic $\mathrm{CO}_{2}$. There is a growing consensus from measurements [Sabine et al., 1999] and from models [Caldeira and Duff,; 2000; Orr et al., 2001] that Mode and Intermediate waters of the Southern Ocean account for between one-third and one-half of the anthropogenic uptake of $\mathrm{CO}_{2}$ by the ocean. Thus the 92 year transit time for the fastest $50 \%$ of the particles corresponding to SAMW provides a model-based estimate of the residence time for $\mathrm{CO}_{2}$ in this important ocean reservoir before reemergence in the surface layer through upwelling within the EUC.

[23] It will be a subject for further investigation to compare this model-based estimate with other independently derived estimates. For example, Fine et al. [2001] used $\mathrm{CFC}$ data to estimate equatorial ventilation timescales of 25-30 years for the $\sigma_{0}=26.8$ density horizon (their Figure 4). The discrepancy between our model-derived advective age and this CFC-derived age will be addressed with an explicit simulation of CFCs. Caution should be exercised in interpreting the advective timescales represented in Figure 3, since the century timescale of the model spinup is of the same order as the advective timescale for intergyre exchange. Caution should also be exercised when comparing output from these runs, which are not eddypermitting, which are forced with climatological fluxes, and which do not capture the critical scales of western boundary currents, in interpreting the exact nature of such "advective ages" [for a discussion of an eddy permitting simulation with Lagrangian trajectories, see Hazeleger et al., 2001]. Nevertheless, the resolution of ORCA2 is similar to that of most models which are currently used to study oceanic uptake of anthropogenic $\mathrm{CO}_{2}$, and thus the model-derived residence time of $\mathrm{CO}_{2}$ in this ocean reservoir is useful in understanding the behavior of such models.

[24] Acknowledgments. We wish to thank our reviewers, as well as Wilco Hazeleger, Daniele ludicone, Gilles Reverdin, Mark Cane, Christophe Menkes, and Greg Johnson for constructive comments. The calculations were performed on the NEC SX-5 at IDRIS (Institut du developpement et des resources en informatique scientifique).

\section{References}

Antunov, J., S. Levitus. T. P. Boyer. M. Conkright. T. O'Brien, and C. Stephens, World Ocean Atlas 1998 Vol. 2: Temperature of the Pacific Ocean, NOAA Atlas NESDIS 27, U.S. Gov. Printing Office, Wash., D.C., 166 pp., 1998.

Blanke, B., and P. Delecluse, Variability of the tropical Atlantic ocean simulated by a general circulation model with two different mixed layer physics, J. Phys. Oceanogr., 23, 1363. 1388, 1993.

Hlanke, $B$, and $S$. Raynatid, Kinematics of the Pacific Equatorial Undercurent: An Eulerian and Lagrangian approach for GCM results, J. Phys. Oceanogr, 27, 1038-1053,1997.

Blanke, B., S. Speich, G. Madec, and K. Döös, A global diagnostic of interocean mass transfers, J. Phys. Oceanogr:, 3/, 1623-1632, 2001

Blanke, B., S. Speich, G. Madec, and R. Maugé, A global diagnostic of interocean ventilation, Geophys. Res. Lett., 29, doi:10.1029/ 2001GLO13727, 2002.

Boyer, T. P.. S. Levitus, I. Antonov, M. Conkright, T. O'Brien, and C. Stephens. World Ocean Allas 1998 Vol. 5: Salinity of the Pacific
Ocean, NOAA Atlas NESDIS 30, U.S. Gov, Printing Office, Wash. D.C., $166 \mathrm{pp}, 1998$.

Caldeira, K., and P. B. Duffy. The role of the Southern Ocean in uptake and storage of anthropogenic carbon dioxide, Science, 287, 620-622, 2000.

Fichefet, T., and M. A. Morales Maqueda, Sensitivity of a global sea ice model to the treatment of ice thermodynamics and dynamics, J. Geophws. Res., 102, 12,609-12,646, 1997.

Fine, R. A., K. A. Maillel, K. F. Sullivan, and D. Willey, Circulation and ventilation flux of the Pacific Ocean, J. Geophys. Res., 106, 22,159$22,178,2001$.

Gent, P. R., and J. C. McWilliams, Isopycnal mixing in ocean circulation models, J. Phys. Oceanogr, 20, 150-156, 1990.

Goosse. H, and T. Fichefet. Importance of ice-ocean interactions for the global ocean circulation: A model study, J. Geophys. Res., 104, 23,337$23,355,1999$.

Gordon, A. L., Interocean exchange of thermocline water. $J$. Geophws. Res., $91,5037-5046,1986$.

Hazeleger, W., P. de Vries, and G. J. van Oldenborgh. Do tropical cells ventilate the Indo-Pacific equatorial thermocline?, Goophlys. Res. Lett., $28,1763-1766,2001$

Hazeleger, W., P. de Vries, and Y. Friocourt, Sources of the Equatorial Undercurrent in the Atlantic in a high-resolution ocean model, $J$. Phys. Oceanogr, in press, 2003.

Hirst, A., and J. Godfrey, The role of the Indonesian Throughflow in a global ocean GCM, J. Phys. Oceomogr, 23, $1057 \cdot 1086,1993$.

Johnson, G. C., and M. J. McPhaden, Interior pycnocline flow from the subtropical to the equatorial Pacific Ocean, J. Phys. Oceanogr., 29, $3073-3089,1999$.

Kalnay, E. C., et al., The NCEPNCAR reanalysis project, Bull. Am. Meteor: Soc. 77, 437-471, 1996.

Liu, Z., S. G. H. Philander, and R. C. Pacanowski, A GCM study of tropical-subtropical upper-ocean water exchange, J. Phys. Oceanogr: 24, 2606-2623, 1994.

Madec, G.. P. Delecluse, M. Imbard, and C. Lévy, OPA 8.1 Ocean General Circulation Model reference manual. Notes du Pole de Modélisation de I'Institut Pierre-Simon Laplace, $11,91 \mathrm{pp}$. (Available from http:// www.lodyc.jussieu.fr/opa), 1998.

McPhaden, M. J., and D. Zhang. Slowdown of the meridional overtuming circulation in the upper Pacific Ocean, Nature, 4/5, 603-608, 2002.

Murtugudde, R., A. Busalacchi, and J. Beauchamp, Seasonal-to-interannual effects of the Indonesian Throughflow on the Indo-Pacific basin, J. Geophys. Res., J03, 21,245-21,441, 1998.

Orr, J. C., E. Maier-Reimer, U. Mikolajewicz, P. Monfray, J. Sarmiento, J. R. Toggweiler, N. K. Taylor, J. Palmer, N. Gruber, L. Le Qauere, R. M. Key, and J. Boutin, Estimates of anthropogenic carbon uplake from four three-dimensional global ocean models, Global Biogeochem. Cycles, 15 , $43-60,2001$.

Rodgers, K. B., M. A. Cane, N. H. Naik, and D. P. Schrag, The role of the Indonesian Throughflow in equatorial Pacific thermocline ventilation, J. Geophys. Res., 104, 20,551-20,570, 1999.

Sabine, C. L., R. M. Key, K. M. Johnson, F. J. Millero, A. Poisson, J. L. Sarmiento, D. W. R. Wallace, and C. D. Winn, Anthropogenic $\mathrm{CO}_{2}$ inventory of the Indian Ocean, Global Biogeochem. Cycles, 13, 179$198,1999$.

Smith, W. H. F., and D. T. Sandwell. Global sea floor topography from satellite altimetry and ship depth soundings, Science, 277, 1956-1962, 1997.

Toggweiler, J., K. Dixon, and W. Broecker, The Peru upwelling and the ventilation of the South Pacific thermocline, J. Geophys. Res., 96, 20,467-20,497, 1991 .

Tsuchiya, M., The origin of the Pacific equatorial 13 degree water, J. Phys. Oceanogr:, 11, 794-812, 1981.

Tsuchiya, M., R. Lukas, R. A. Fine, E. Firing, and E. Lindstrom, Source waters of the Pacific Equatorial Undercument, Prog. Oceanogr, 23, 101 147. 1989.

K. Rodgers, P. Ciais, and J.-C. Dutay, LSCE'LPSL, Bat. 709, CE L'Orme des Merisiers, F-91191 Gif sur Yvette, France. (rodgers(a)lodyc.jussieu.fr; ciais@lsce.saclay.cea.fr: dutny (alsce.saclay.cea.fr)

B. Blanke, Laboratoire de Physique des Océans. CNRS-IFREMER-UBO, 6 avenue Le Gorgeu. BP 809, 29285 Brest Cedex, France. (blanke(ajunivbrest.fr)

G. Madec and O. Aumont, LODYC, Universite Pierre et Marie CurieCase 100, 4 Place Jussieu, 75252 Paris CEDEX 05, France. (gm(alodyc. jussicu.fr; aumont(wlodyc.jussieu.fr) 